\title{
Factors Influencing on Purchasing Formula Milk for Babies: An Empirical Research in Hanoi
}

\author{
Pham Thi Thanh Hong ${ }^{1}$ \\ ${ }^{1}$ Hanoi University of Science and Technology, Vietnam \\ Correspondence: Pham Thi Thanh Hong, Hanoi University of Science and Technology, Vietnam. E-mail: \\ hong.phamthithanh@hust.edu.vn
}

Received: August 12, 2015

Accepted: August 31, $2015 \quad$ Online Published: September 4, 2015

doi:10.5430/ijba.v6n5p37

URL: http://dx.doi.org/10.5430/ijba.v6n5p37

\begin{abstract}
This paper aimed to get the insights of consumer behavior in formula milk market. By implementing a survey with sample size of 97, the research investigated the factors influencing behavior of formula milkbuyer. Research examined and approved that all 4 factors (cultural, social, personal and psychological factor) equally influence on purchasing formula milk for babies in Hanoi. Research also concluded that domestic formula milk producers should attain their customers by committing high quality, adding more values for nurturing babies, setting right price, and providing sufficiently information.
\end{abstract}

Keywords: formula milk for babies, empirical research, Hanoi market

\section{Introduction}

Vietnam is a potential market for dairy producers. According to UNICEF today Vietnam has about 26 million children. The population of newborn to 4-year-old children will increase by 3.6\% during 2010-2015 (General Statistics Office, 2010; Nordic, 2011). It is expected that this segment will have a promising growth, posting CAGR of $11.25 \%$ in volume and $14.43 \%$ in value for 2010-2013, as projected by Euromonitor (2012). In the year of 2014, Vietnam dairy industry is expected to continue growing at a high rate. Reason is that the per capita income of Vietnamese continually increases. Thus, the demand for dairy products in general and formula milk for babies in particularbecome bigger and bigger, while as the domestic production cannot meet demands.

However, in Vietnam, there exist some factors that do not support the domestic milk powder manufacturer. While domestic producers have made big effort to modernize the manufacturing lines as well as to improve the quality in order to reach the needs of consumers, consumers prefer foreign brands to local brands by choosing formula milk for their kids.

In order to address the issues and find out recommendationsfor the problems, this research examines the factors affecting behavior and purchasing decision of formula milk consumers.

\section{Research Design}

2.1 Research Models and Hypothesis

According to Philip Kotler (2011), there are four factors that affect the consumer buying decisions including: (1) cultural factor, (2) social factor, (3) psychological factor, and (4) personal factor. Taking the concepts of consumer stimuli of Philip Kotler, this research used the following research model (see Figure 1). 


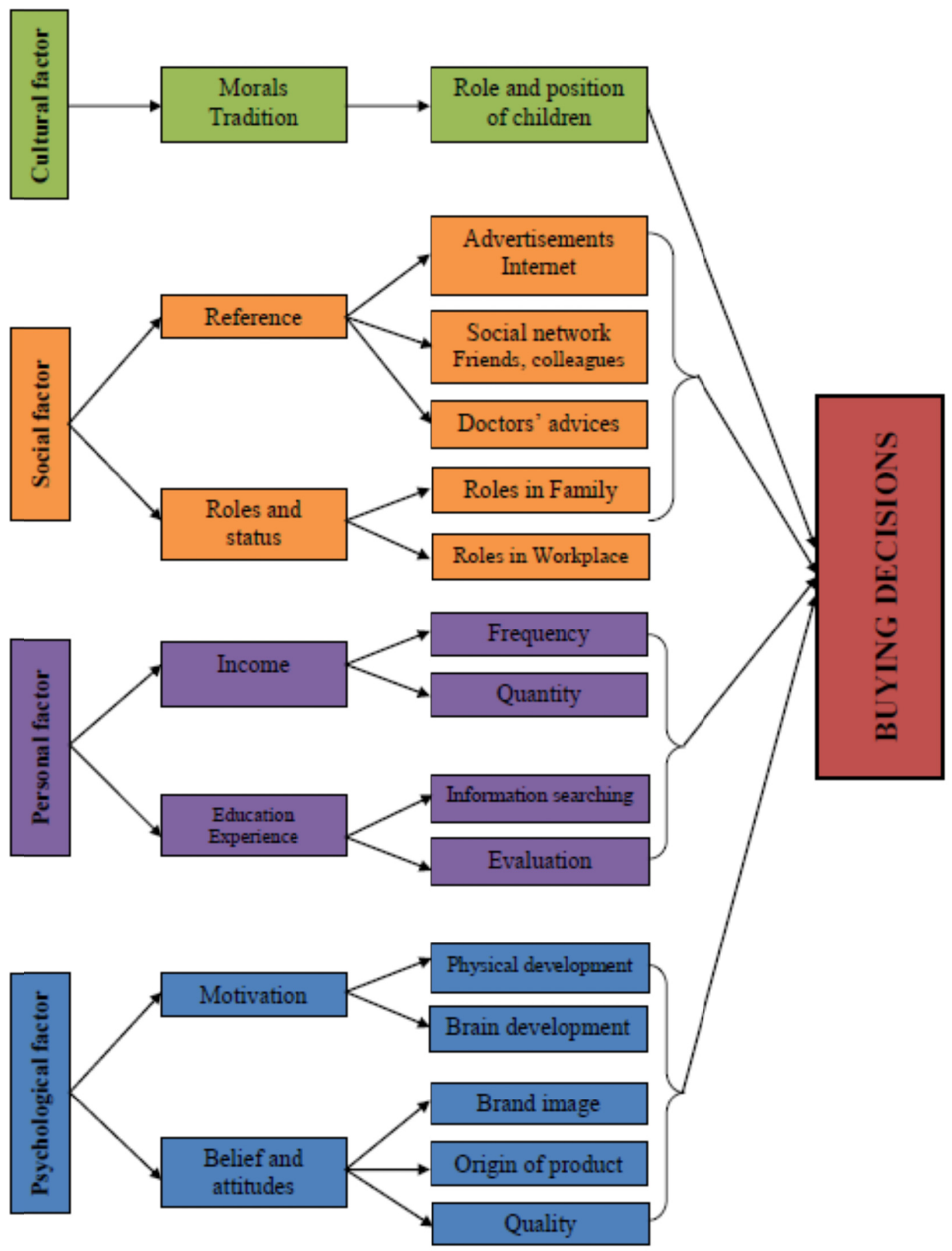

Figure 1. Research model

Source: Author's compilation

The fact is that, in Vietnam, children are considered as one family's future, happiness, and honor as well. They are expected to be special family members who take over the tasks of upholding and developing family's tradition as well as lineage. Then, parents can minimize their owned needs for luxuries, fashion, vehicles, hobbies, or entertainments in order to save money to have best condition for their children including diet and education.

Hypothesis 1 (H1): Cultural factors like morals and tradition impact positively on buying decision.

One of the most concerns of parents is how to raise their children healthy and smart. They may take the advice 
directly or indirectly family members, friends, colleagues, neighbors, a social network, a fan club, and the like. They may be influenced by companies' advertisements as well. In the early stage of a child, they may sometime have health problems or illness. With the professional background, besides giving medical advices for parents, doctors or nutritional specialists can also give recommendations about the feeding methods or nutritional needs for children (Nordic, 2011).

\section{Hypothesis 2 (H2): Social factors have positive impact on buying decision.}

Today parents pay more attention to nutritional needs and the healthy growth of their children. They are aware that diet plays the most important role in growing the height, weight and body proportion of a child. All of them are also want their children will be intelligent and smart. Beside some factors affecting brain growth like genetic factor, outsides effects, physical activities, and mental stimulation... diet of the child is considered as one of an important factor (Nordic, 2011). Formula milk added some extra ingredients supporting brain development like DHA, ARA or Tourine, $\mathrm{A}+\ldots$ are choosing by parents.

By the way, in selection of the trademark to buy, consumers always consider the quantity and frequency of using the product before making buying decision due to their limited income (Fred and Alam, 2002; Heesup and Kisang Ryu, 2012).

Based on their knowledge and experience people searching information about the product they intend to buy and evaluate them (Ziya et al., 2006; Solomon et al., 2006; Devine, 2005; Colonna et al., 2011)

Hypothesis 3 (H3): Personal factors have positive impact on buying decision.

Due to the economic problem before Doi-Moi 1986, Vietnamese people always preferred imported goods and products for better quality, better designed. Now a day, although the economy has developed rapidly and many goods and products have been produced in land, but the belief in imported goods with their well-known brand, origin of product and their quality is considered unchanged (Fulbright, 2010).

Hypothesis 4 (H4): Psychological factors positively influence the buying decision.

\subsection{Data Collection}

The research collected data by sending questionnaires via social network such as lamchame.com, webtretho.com, chamsocbe.com, nhatkybe.vn.... These social networks are deserved for parent to share information of taking care and raise their children. During the time of May and June 2015, the research received above 120 feedbacks and only 97 are qualified to analyze.

\section{Results and Discussion}

\subsection{Sample Description}

Based on the collected data, which was analyzed by SPSS, it was seen that most responses are female with $81.82 \%$, meanwhile only $18.18 \%$ are male.

The biggest group belongs to the age range from 30-40 years old with $55.08 \%$, who are old enough to have a family with one or two children. About one of four is responses in the age range from 20-30 years old. Only 1.07\% is under 20 years old.

More than half people asked are graduated. The second biggest group belongs to post-graduated people. $10.16 \%$ responses are high school graduated and $14.97 \%$ are college graduated.

Reflected from the under table, a massive feedbacks (about 83.96\%) are full-time jobs. Freelancers are counted for only $6.95 \%$. People with part-time job (with $3.74 \%$ ) are equal to others (like retired people, doing own business...). Only $5.34 \%$ is unemployed.

About one in three respondents (34.22\%) has income from 10 million VND to 20 million VND. $31.02 \%$ have income from 5 million VND to 10 million VND. $22.46 \%$ earn monthly from 2 million to 5 million VND. 20 persons (equivalent $10.7 \%$ ) belong to the group having income more than 20 million VND. The smallest proportion is income group less than 2 million VND per month accounted for only $1.6 \%$.

As the result of the survey, people having children older than 6 years old account for $33.16 \%$ and children in the age range from 2 to 6 years old accounted for $29.95 \%$. 9.63\% belong to people whose children are from 6 months to 1 year. The number of respondents having infants is $11.76 \%$ and number of children from 1 to 2 years old is $15.51 \%$.

Five levels were set up to investigate, how much do people pay for milk powder for their children in comparison with their income. However, 2 levels $(0 \%$ and over $60 \%)$ were not chosen. That means that all respondents have 
purchased and used milk powder for their children. And nobody has paid more than $60 \%$ of their income for formula milk for their children. The greatest proportion (65.24\%) belong people who pay less than $20 \%$ of their income for purchasing milk. About one third (34.22\%) people asked have paid from $20 \%$ to $40 \%$ of their income for milk purchasing. Only one person (equivalent $0.53 \%$ ) asked paid from $40 \%$ to $60 \%$ of his/her income for milk powder.

Answering for the question"which milk product they prefer to choose for their children, imported mild powder or domestic produced milk powder", more than half (57.75\%) gave feedback that they have chosen imported milk, meanwhile $42.25 \%$ chosen domestic produced milk for their children.

\subsection{General Satisfaction and Purchasing Intention for Domestic Produced Milk}

Most respondents are satisfied with the product they chosen. Only $17.11 \%$ answered that they are unsatisfied with the milk product using for their children.

Based on the survey result, we can see that a huge number of respondents $(83.96 \%)$ having intention to purchase domestic produced milk for their children. Only a small proportion (16.04\%) will not choose domestic products.

\subsection{Reliability}

The research run Cronbach's Alpha test to make sure that the survey is appropriate for measuring all factors. According to Cronbach's Alpha (see Table 1), all tested values are higher than 0.6 are acceptable and reliable. From the analyzed results in the table above, the value of cultural factors (C1-3), Social factors including reference and mother's roles and status (R1-3, S1-4), Personal factors (P1-4), Psychological factors including motivation and expectation (Ph1-5) and Imported milk evaluation ... is higher than 0.6. Therefore, questions for measuring all factors and imported milk evaluation as buying decision construct have high reliability and meet standards for study purposes.

Table 1. Cronbach's Alpha test

\begin{tabular}{lccc}
\hline & No of Items & $\begin{array}{c}\text { Number of } \\
\text { respondents }\end{array}$ & Cronbach's Alpha \\
\hline Cultural factors & 3 & 97 & 0.726 \\
\hline Social factors & 5 & 97 & 0.710 \\
\hline Personal factors & 4 & 97 & 0.667 \\
\hline Psychological factors & 5 & 97 & 0.629 \\
\hline Imported milk evaluation as buying decision construct & 4 & 97 & 0.602 \\
\hline
\end{tabular}

Source: Authors' compilation

\subsection{Descriptive Analysis}

\subsubsection{Descriptive Analysis of Cultural Factors}

Three indicators for measuring the cultural factors were tested. The result showed a quite high mean value of each indicator $(4.02 ; 4.41 ; 4.63)$. That means, traditionally, children have a very important position in each Vietnamese family. Therefore, taking care for childrenalways is in the top priority.

\subsubsection{Influences of Social Factors}

\section{Influences of Reference factors}

There are 3 indicators for investigating the influences of reference factors like: (1) Advertisements on TV, internets, (2) Recommendations and advices of friends, colleagues... and (3) Consulting of doctors.

These indicators have mean values from 3.02 to 3.88. That is not quite high but acceptable. We can see that reference factors influence also purchasing decision, but not significantly.

\section{Influences of Mother's Roles and Status}

Four indicators were set up in order to measure the effects of roles and status of a mother. All mean values are higher than average level (2.50). The highest mean value (4.09) belongs to the role of mother in family, who bears the main responsibility for preparing meals for family. 
Additionally, the status of mother like job and career development has significant impact on purchasing decision too (mean value from 3.89 to 3.48 ).

\subsubsection{Influences of Personal Factors}

For the purpose of research impacts of personal factors, following indicators were tested by 97 respondents: (1) Income of consumer, (2) Education/Understanding of consumer and (3) Experience and Evaluation of consumer.

And the feedbacks are nearly similar, the mean values ranging from 3.92 to 4.20 showed the agreement of people asked. Most respondents (89.3\%) agree that "income influences their buying decision by choosing formula milk for their children". In addition, many parents $(65.24 \%)$ have also monitored the quality as well as the effects of chosen product before giving next buying decision.

\subsubsection{Influences of Psychological Factors}

In this part, most people asked (mean value: 4.53) agreed that their expectation for health, physical and brain development of the children effects greatly their buying decision.

All other indicators including quality, origin, brand and price of products have quite high mean values from 3.63 to 4.50. The results indicate that these indicators have big impact on purchasing decision.

\subsubsection{Imported Milk Evaluation as Buying Stimuli}

Aiming at understanding the assessment of consumers on imported formula milk, 4 indicators were tested: Quality, brand, promotion and price of imported milk.

The first three mean values ranging from 3.23 to 3.40 are a bit higher than average level.

More respondents agreed that quality, brand and promotion of imported milk are better than domestic produced milk. However, a big number of them (75.94\%) also acknowledged that the price of imported milk is higher than domestic produced formula milk.

\subsection{Hypothesis Testing}

\subsubsection{Simple Regression}

In order to test the relationship between 4 independent variables and dependent variable (buying decision) simple regression was carried out. The results were gathered in the table below.

Table 2. Simple regression's result

\begin{tabular}{lrrrrr}
\hline \multirow{2}{*}{ Independent variables } & \multicolumn{4}{c}{ Dependent variable (Buying Decision - BD) } \\
\cline { 2 - 7 } & $\mathbf{R}^{\mathbf{2}}$ & Adjusted $\mathbf{R}^{\mathbf{2}}$ & $\begin{array}{c}\text { Standardized } \\
\text { coefficient (Beta) }\end{array}$ & $\mathbf{t}$ & Sig. \\
\hline Cultural Factor (CF) & 0.427 & 0.421 & 0.653 & 8.544 & 0.000 \\
\hline Social factor (SF) & 0.366 & 0.360 & 0.605 & 7.526 & 0.000 \\
\hline Personal factor (PF) & 0.380 & 0.374 & 0.616 & 7.749 & 0.000 \\
\hline Psychological factor (PSF) & 0.400 & 0.393 & 0.632 & 8.076 & 0.000 \\
\hline
\end{tabular}

The results indicate that there exist statistically significant relationships between all 4 independent variables and the buying decision variable with $\mathrm{p}<0.001$. As a consequence, all following 4 hypotheses are approved.

Hypothesis 1 (H1): Cultural factors impact significantly buying decision

Hypothesis 2 (H2): Social factors impact significantly buying decision.

Hypothesis 3 (H3): Personal factors impact significantly buying decision.

Hypothesis 4 (H4): Psychological factors impact significantly buying decision.

\subsubsection{Multiple Regressions}

The multiple regressions model is conducted to build a function of the relationship between 04 independent variables $\mathrm{CF}, \mathrm{SF}, \mathrm{PF}$ and PSF and the dependent variable BD. 
Table 3. Multiple regressions' result

\begin{tabular}{|c|c|c|c|c|c|}
\hline \multirow{3}{*}{ Independent variables } & \multicolumn{5}{|c|}{ Dependent variable (Buying Decision - BD) } \\
\hline & \multicolumn{2}{|c|}{ Unstandardized coefficients } & \multirow{2}{*}{$\begin{array}{c}\text { Standardized } \\
\text { coefficients (Beta) }\end{array}$} & \multirow{2}{*}{$\mathbf{t}$} & \multirow{2}{*}{ Sig. } \\
\hline & B & Std. Error & & & \\
\hline (Constant) & .173 & 206 & & .840 & .403 \\
\hline Cultural Factor (CF) & .224 & .034 & .347 & 6.530 & .000 \\
\hline Social factor (SF) & .273 & .044 & .322 & 6.263 & .000 \\
\hline Personal factor $(\mathrm{PF})$ & .222 & .043 & .277 & 5.201 & .000 \\
\hline $\begin{array}{l}\text { Psychological factor } \\
\text { (PSF) }\end{array}$ & .233 & .039 & .315 & 5.980 & .000 \\
\hline & 791, Adjus & $0.782, \mathrm{~F}=89$ & 7, Sig. $=.000$ & & \\
\hline
\end{tabular}

The results from multiple regression analysis shows that all 4 independent variables have positive relationshipswith dependent variable $($ at $\mathrm{p}<0.001)$. The positive relationship between cultural factor, social factor, personal factor and psychological factorare reconfirmed.

\section{Conclusion}

The study reveals that children play a very important rolewithin each family. Vietnamese parents traditionally want to provide the best condition for their children. That is why they chose the best dairy products according to their considerations for their children. In this case, it is necessary for producers and contributors to improve product quality and communicate such issue to their customers.

According the survey, it is seen that mothers acknowledge the role of breast feeding. They know that, breast feeding for the first few years of life is very important. It protects children from illness, provides ideal, safe and economical sources of nutrients. However, more and more women due to work pressure have to chooseformula milk for their children. It is necessary to provide them educating about good nutrition, early childhood nutritional needs and brain development. It is an ideal chance for milk producers for advertising their products. Through workshops and educational events for supporting mothers and health care professionals in maternal and infant health with many participants, their brands as well as reputation are acknowledged. Foreign players have been very successful in such marketing strategies. Abbott is an example. In order to building company's brand, they have not only invested in advertising and promotion but also in sponsor educational program or introduced nutrition consultation rooms in pediatric hospitals, where health care professionals provide parents with essential nutrition information and techniques for feeding their children (Abbott, 2012).

The results also show that prices of imported milk are higher than domestic one. However, the number of people chose imported milk for their children is significant big with 58\% interviewees. This may come from the fact that consumers interpret higher prices as a signal of superior quality and lower prices as sign of inferior quality. In Vietnam, it is said that, parents prefer expensive milk than cheap ones because they worry about the quality of products. Additionally, consumers seem satisfied with the productsthat they have paid more to obtain. They think that: "Everything has their owned price". Thus, domestic firms and lower-price producers should consider if lowering prices is the right strategy for developing brand and gaining market share from foreign players or it just hurt the brand.

Besides, number of domestic and foreign dairy companies in the market is large. In supermarkets, hundreds of products can be found in shelves. There is even competition for best location in supermarket between brands. Thanks to this product differentiation, formula milk market could be considered as a competitive market, and milk consumers have enough brands to select. However, it can be said that it is not a perfect market, because it is very difficult for consumers to access to product information (Fulbright, 2010). Before making buying decision, consumers want to screenproduct characteristics and quality. In fact, producers or sellers do not disseminate much information to the buyers.

Because in the site of the customer, it is quite difficult to screen the product quality, the control of the government becomes very important. Inspectors are responsible for routine test and examination in order to ensure that products meet all quality, safety, and hygiene standards. Inspection results should be published officially and frequently. Besides, consumer association should act more effectively. In developed countries, such associations are very active in consumer protection. In contrast, the functions and activities of consumer association in Vietnam are quite limited, even in providing assistance and advice for consumers, providing product information, or conducting studies and 
research as well.

Another point is that consumers also lack information about prices. They cannot gather enough information of pricesto compare before buying. In addition, Vietnamese people have a habit of buying milk in smaller, local shops than in supermarkets, where prices are listed on the products. In order to control the powdered milk price, from 01.6.2014, the government has applied price registration and regulation policy for 25 powdered milk products for children under 6 years old. This shows the government aims to reduce or stabilize price of dairy products. Then, consumers now can easily access price information and doing comparison before choosing.

In conclusion, the author hopes that consumers can understand themselves more deeply. They also have to protect themselves from harm through careful screening characteristics and quality of products. They should not trust advertising and signaling of producers and sellers. The powdered milk market provides them a wide range of choices. They should becomesmart consumers. The government has tried to protect consumers through product inspection and price control policies. Additionally, domestic producers should invest more in advertising and brand development. They need to reassure consumers that their quality standards are as high as well-known and expensive foreign brands.

Due to limitation of time, the survey was only carried out in Hanoi. Thus, the research results maybe did not reflect all customers' characteristics. Further research should be implemented not only in big cities, but also in provinces. Another limitation is that, email was the only channel to collect data. However, people with lower education, lower job position, and lower income rarely access to the Internet. Thus, the results of the research could not be adequate. In future, the research should take place with other channel of collecting data to cover more various types of respondents.

\section{References}

Abbott. (2012). Abbott Vietnam Citizenship report.

Colonna, A., Durham, C., \& Meunier-Goddik, L. (2011). Factors affecting consumers' preferences for and purchasing decisions regarding pasteurized and raw milk specialty cheeses. Journal of Dairy Science, 94(10), 5217-5226. http://dx.doi.org/10.3168/jds.2011-4456

Devine, C. M. (2005). A Life Course Perspective: Understanding Food Choices in Time, Social Location, and History. Journal of Nutrition Education and Behavior, 37(3), 121-128. http://dx.doi.org/10.1016/S1499-4046(06)60266-2

Euromonitor International: Country Sector Briefing. (2009). Other Dairy Products - Vietnam.

FAO. (2011). Food Outlook, Global Market Analysis.

FAO. (2012). Food Outlook, Global Market Analysis.

Fred, G., \& Alan, G. I. (2002). The behavioral life-cycle theory of consumer behavior: survey evidence. Journal of Economic Behavior \& Organization, 48, 391-401. http://dx.doi.org/10.1016/S0167-2681(01)00242-6

Fulbright Economics Teaching Program. (2011-2012). Powder milk for children under 6 years old in Vietnam.

Heesup, H., \& Kisang, R. (2012). The theory of repurchase decision-making (TRD): Identifying the critical factors in the post-purchase decision-making process. International Journal of Hospitality Management, 31, 786-797. http://dx.doi.org/10.1016/j.ijhm.2011.09.015

Muammer, O. (2005). Factors which influence decision making in new product evaluation. European Journal of Operational Research, 163, 784-801. http://dx.doi.org/10.1016/j.ejor.2003.11.002

Nordic Industry development. (2011). Brief Sector Overview: Dairy Industry in Vietnam.

Phillip, K. (2011), Marketing Management. Prentice Hall.

Shiler, Z., Filter, S., \& Dubowski, S. (2007). Time optimal paths and acceleration lines of robotic manipulators. Proceedings of the 26th Conference on Decision and Control, p. 98-99.

Solomon, M., Bamossy, G., Askegaard, S., \& Hogg, M. K. (2006). Consumer Behaviour: A European Perspective ( $4^{\text {th }}$ ed.). Harlow: Prentice Hall.

Ziya Gokalp Goktolga, Sibel Gulse Bal, \& Osman Karkacier. (2006). Factors effecting primary choice of consumers in food purchasing: The Turkey case. Food Control, 17, 884-889. http://dx.doi.org/10.1016/j.foodcont.2005.06.006 